OPEN ACCESS

Edited by:

James Donald Fortenberry,

Emory University, United States

Reviewed by:

Daniela De Souza,

University of São Paulo, Brazil

Katherine Cashen,

Duke University, United States

*Correspondence:

Erin F. Carlton

ecarlton@med.umich.edu orcid.org/0000-0002-6206-0514

Specialty section:

This article was submitted to Pediatric Critical Care, a section of the journal

Frontiers in Pediatrics

Received: 20 August 2021

Accepted: 20 October 2021

Published: 15 November 2021

Citation:

Carlton EF, Weiss SL, Prescott HC and Prosser LA (2021) What's the

Cost? Measuring the Economic

Impact of Pediatric Sepsis.

Front. Pediatr. 9:761994.

doi: 10.3389/fped.2021.761994

\section{What's the Cost? Measuring the Economic Impact of Pediatric Sepsis}

\author{
Erin F. Carlton ${ }^{1,2 \star}$, Scott L. Weiss ${ }^{3,4}$, Hallie C. Prescott ${ }^{5,6}$ and Lisa A. Prosser ${ }^{2,7}$ \\ ${ }^{1}$ Division of Critical Care Medicine, Department of Pediatrics, University of Michigan, Ann Arbor, MI, United States, ${ }^{2}$ Susan B. \\ Meister Child Health Evaluation and Research Center, Department of Pediatrics, University of Michigan, Ann Arbor, MI, \\ United States, ${ }^{3}$ Department of Anesthesiology and Critical Care, Children's Hospital of Philadelphia, University of \\ Pennsylvania Perelman School of Medicine, Philadelphia, PA, United States, ${ }^{4}$ Pediatric Sepsis Program, Children's Hospital \\ of Philadelphia, Philadelphia, PA, United States, ${ }^{5}$ Veterans Affairs Center for Clinical Management Research, Health Services \\ Research \& Development Center of Innovation, Ann Arbor, MI, United States, ${ }^{6}$ Department of Internal Medicine, Division of \\ Pulmonary and Critical Care, University of Michigan, Ann Arbor, MI, United States, ${ }^{7}$ Department of Health Management and \\ Policy, School of Public Health, University of Michigan, Ann Arbor, MI, United States
}

Sepsis, life-threatening organ dysfunction secondary to infection, hospitalizes nearly 75,000 children each year in the United States. Most children survive sepsis. However, there is increasing recognition of the longer-term consequences of pediatric sepsis hospitalization on both the child and their family, including medical, psychosocial, and financial impacts. Here, we describe family spillover effects (the impact of illness on caregivers) of pediatric sepsis, why measurement of family spillover effects is important, and the ways in which family spillover effects can be measured.

Keywords: sepsis, family, finances, pediatric, financial toxicity

\section{INTRODUCTION}

Sepsis and septic shock result in the hospitalization of nearly 75,000 children each year in the United States (1). Increasingly, the impacts of sepsis beyond acute hospitalization are recognized. Children commonly experience declines in quality of life (QOL) (2-4), increased need for subspecialty care (5), and new dependence on medical devices (6). It is clear that sepsis causes long-term sequelae in children. What is less known, however, is the impact of sepsis on a child's family.

Post-Intensive Care Syndrome Pediatrics (PICS-p) is a framework which describes the broad sequelae of critical illness, such as sepsis, that are experienced by children and their families $(7,8)$. Importantly, PICS-p recognizes the bidirectional relationship of a child and their family, with childhood illness affecting caregiver health, and caregiver health subsequently influencing a child's recovery from illness (9). Caregivers often experience stress, anxiety, and depression during and after their child's sepsis hospitalization (10) which can impair a child's recovery.

Beyond exerting a toll on caregiver physical and mental health, sepsis hospitalization may also result in financial costs (e.g., co-pays, transportation, lodging) and additional caregiving burden (e.g., remaining at a child's bedside during hospitalization, a child's new medical needs, follow-up appointments). This financial and caregiving burden can in turn influence recovery. For example, a child's sepsis hospitalization may limit caregivers' ability to work outside the home, thereby causing or exacerbating financial strain, which may impair a child's return to health. The effect of a patient's health on family outcomes, termed "family spillover effects," has been studied extensively by economists in chronic illnesses (11) such as Alzheimer's Disease (12), autism (13-15), and childhood cancer (16). In this article, we describe family spillover effects, why they should be evaluated in pediatric sepsis, and how they can be measured. 


\section{WHAT ARE FAMILY SPILLOVER EFFECTS?}

First described in 2005, family spillover effects recognize that the change in an individual's health can have substantial impacts on the QOL of their family members (17). Simply put, family spillover effects are the direct and indirect impacts of a patient's health on the financial, emotional, and physical health of their family members or caregivers. These effects can be negative (e.g., financial strain, poor sleep) or positive (e.g., sense of fulfillment) (18). Spillover effects are often organized into three categories: QOL impacts, financial costs, and informal caregiving costs (Figure 1). QOL impacts describe the physical, emotional, and social impact resulting from having a sick loved one. The financial costs include out-of-pocket costs such as co-pays, deductibles, and other costs of care not covered by insurance (e.g., transportation, durable medical equipment). Informal caregiving costs encompass the unreimbursed care provided by family members (19), and includes the time-cost involved in caregiving (20).

Family spillover effects result both from providing care and from worrying about others $(12,21)$. Those affected are not limited to the nuclear family or those providing care, and may include siblings, friends, or other relatives (12). Similarly, spillover effects involve physical and emotional health and wellbeing, interpersonal relationships, and finances or employment. Spillover effects may subsequently cause the patient to have feelings of guilt or worry. For example, a child recovering from sepsis may feel guilt about their parent's stress or work absence.

While spillover effects have been studied primarily in the context of chronic disease, acute illness and hospitalization likewise impact caregivers QOL and result in both financial and informal caregiving costs. Parents or caregivers report decreased QOL, especially during the acute hospitalization period $(22,23)$.
Families of hospitalized children commonly describe significant financial costs (24), most often related to their child's medical care. Similarly, a child's health impacts parental employment, with higher rates of unemployment or leaving the workforce among family members of children with a chronic illness $(25,26)$. The need for informal caregiving may result in frustration for employed parents as they describe a lack of leave entitlement and ability for flexible arrangements needed for child care (27). While the Family Medical Leave Act provides eligible workers up to 12 weeks of leave, only $56 \%$ of U.S. employees are eligible and the leave is unpaid, which may further exacerbate these family spillover effects (28). Indeed, $40 \%$ of parents of children with special health care needs report returning to work sooner than what the parent thought was needed for their child's health, and this was largely due to financial need (29). As children with chronic illness account for a significant portion of pediatric sepsis hospitalizations (30), it is likely many families are experiencing these challenges during hospitalization and beyond.

\section{Evidence of Spillover Effects of Sepsis}

Pediatric critical illness, such as sepsis or septic shock, greatly impacts parent and caregiver mental health and health-related QOL(HRQOL) (Figure 1). Many parents experience acute stress disorder, post-traumatic stress symptoms, anxiety, or depression (8). Children with septic shock can experience emotional difficulties which in turn lower their HRQOL (31). Among adult patients with chronic critical illness or sepsis, caregivers often experience depression, post-traumatic stress symptoms and decreased HRQOL following their loved one's ICU hospitalization (32-34).

After pediatric sepsis, many children experience declines in health, which may increase family financial burden and need for informal caregiving. For example, 1 in 20 children have a

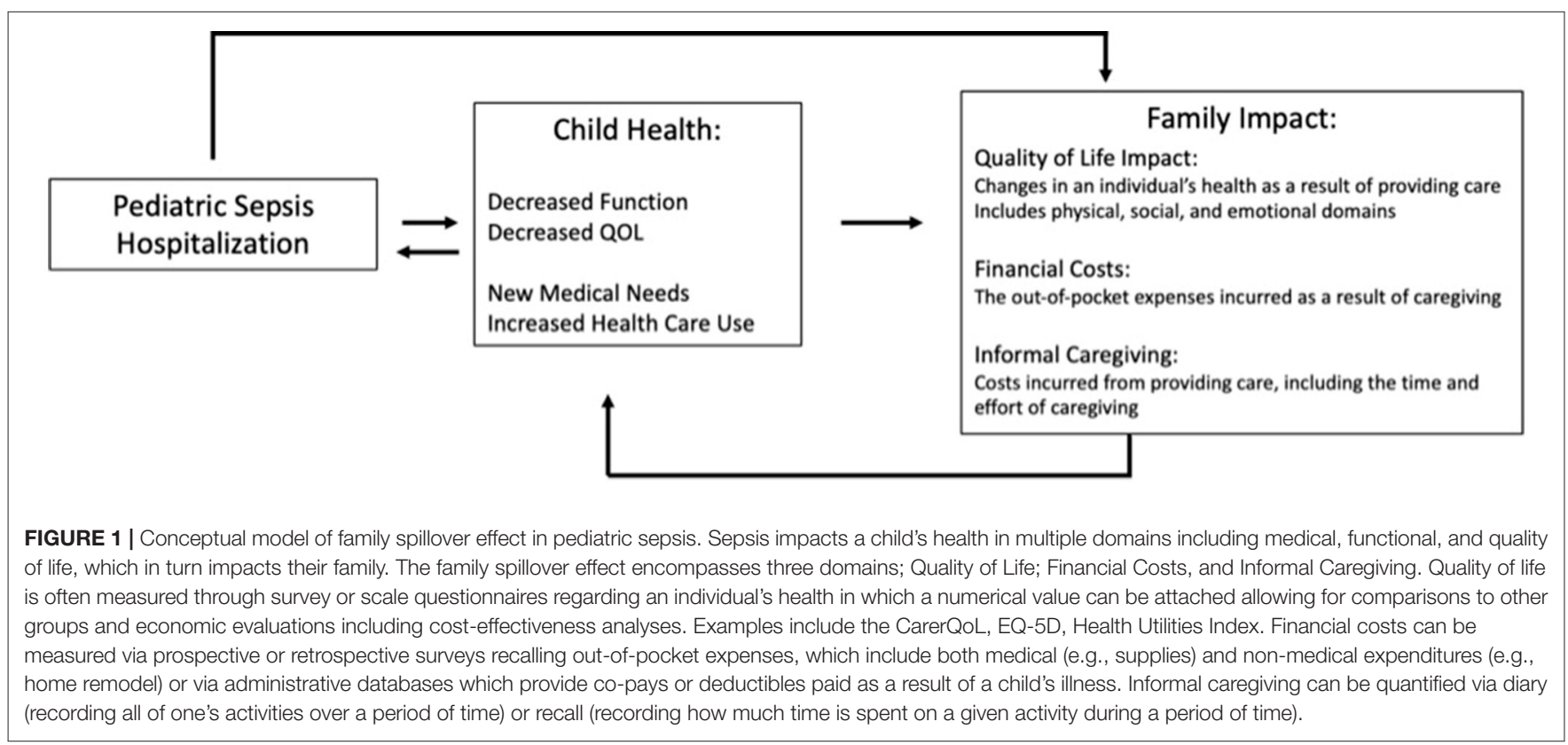


new medical device placed during their sepsis hospitalization (6). Tracheostomy for prolonged mechanical ventilation, one of the most common procedures performed during sepsis hospitalizations, has been associated with significant hardship for families (35). Additionally, there is a substantial increase in the number of outpatient appointments in the year after sepsis hospitalization, reflecting the increase in medical complexity and/or vulnerability after sepsis (5). Finally, nearly one-third of children with sepsis are re-hospitalized in the months following discharge (36). Taken together, the high burden of care and risk for further health deterioration after pediatric sepsis may result in several spillover effects including parental stress, increased caregiving requirements, work absenteeism, and financial burden.

\section{WHY SHOULD WE MEASURE FAMILY SPILLOVER EFFECTS IN SEPSIS?}

Family spillover effects can encompass a wide range of individuals and domains. These family spillover effects must be measured in order to quantify the full burden experienced by a family unit (12). Furthermore, recognizing the impact of sepsis on families may improve the understanding and care of pediatric sepsis survivors-for example, by identifying when family financial strain limits the ability to follow-up or carry out the medical plan (18). Recognition of these spillover effects is important not only during sepsis hospitalization, but also after hospitalization when the majority of financial costs and informal caregiving costs occur (37). Indeed, the importance of family is highlighted within the PICS-p framework $(7,8)$, with calls to action for further study and understanding (9).

In order to deliver the most effective and efficient health care, we must not only look at patient centered outcomes, but also understand the consequences of both the acute illness and interventions rendered (38). To do this, especially within pediatrics, the health, social, and economical effects on families must be studied. Indeed, in addition to their child's health and well-being, families prioritize the outcomes of overall family well-being, social and financial support after critical illness (39).

The formal measurement of family spillover effects differs from the assessment of family outcomes in PICS-p since measurement of spillover effects quantifies the specific economic burden or cost of disease. Because of this formal quantification, family spillover effects can be incorporated into cost-effectiveness and cost-utility analyses to directly measure the relative value of specific interventions. And while the negative health impacts of pediatric sepsis should in itself be enough to drive policy change such as paid time off, finite resources require funders to examine not only health benefits, but the resources required (38). Economic evaluations provide clinicians and policy makers alike a more complete assessment of the value of an intervention (the added benefit and at what cost) (40). This can be applied when comparing interventions in a clinical setting, as well as when considering allocation of financial and resource support (40). A recent systematic review of economic evaluations of adult sepsis demonstrated a large gap in the literature, with many commonly used inventions, such as vasoactive medications and steroids, not included in prior economic evaluation studies (41). Quantifying the impact on the family and measuring the specific economic cost of interventions may drive policy geared toward supporting families and children such as in-home nursing care, transportation/parking stipends, or reimbursement for caregiving.

In the past decade, post-discharge outcomes have been increasingly measured in children hospitalized for critical illness (42). Nearly $20 \%$ of studies included in a recent scoping review of outcomes after pediatric critical illness included evaluation of family members (42). Measures of family outcomes largely focus on HRQOL and mental health, such as anxiety, depression, and post-traumatic stress-but the financial costs and caregiving costs are rarely measured.

\section{HOW CAN WE MEASURE FAMILY SPILLOVER EFFECTS IN SEPSIS?}

The three domains of family spillover effects (QOL, financial costs, and caregiving costs) are most often measured through survey or scale methodologies. Qualitative studies have also described the financial impact of critical care hospitalization on family members and caregivers (43), but quantitative enumeration of family spillover effects is needed for inclusion in an economic evaluation. Finally, spillover effects may be measured via linkage to other administrative data sources, such as employment records.

Quantitative surveys of family spillover effects vary in subject domain, length, and target population and largely focus on QOL measures. Commonly used surveys include the Medical Outcomes Study 36-item Short-Form Health Survey, PedsQL (measure of child QOL), CarerQoL, EQ5D, Self-rated Scale for Post-Traumatic Stress Disorder, General Health Questionnaire, and Parental Stressor Scale: Pediatric Intensive Care Unit (Table 1). They have been used in a general ICU $(42,51$, $52)$, pediatric chronic conditions $(53-55)$, and sepsis $(2-4,56)$ populations. Some of these measures, including the EQ5D, can be used to derive Quality Adjusted Life Years (QALYs) and support cost-effectiveness analyses (57). Additionally, QOL can also be assessed through direct valuation techniques such as standard gamble, in which participants are asked to choose between two options, one that is certain and one that is not, or time-trade off which asks participants to choose between time at a certain health state versus shorter time in full health, followed by a lesser health state $(58,59)$. Finally, surveys such as the Comprehensive Score of Financial Toxicity (48), InCHARGE Financial Distress/Financial Well-being Scale (49), and Financial Distress Questionnaire (50) have been used to capture the financial burden of illness among families.

While economic burden has been measured by linking national survey studies to administrative claims data among adult patients (60), this has been less readily available for many pediatric populations. Thus, primary data collection, such as surveys or family diaries to measure financial burden, are often needed. This methodology relies on survey and applied 
TABLE 1 | Select instruments used to measure family spillover effects.

\begin{tabular}{|c|c|c|c|c|c|}
\hline Instrument & Description & $\begin{array}{l}\text { Number of } \\
\text { questions }\end{array}$ & $\begin{array}{l}\text { Information } \\
\text { source }\end{array}$ & Availability & $\begin{array}{l}\text { Adapt to } \\
\text { quality } \\
\text { adjusted life } \\
\text { years }\end{array}$ \\
\hline \multicolumn{6}{|l|}{ Quality of life } \\
\hline Health utility index (44) & $\begin{array}{l}\text { Measures health status and health related } \\
\text { QOL including dimensions: vision, hearing, } \\
\text { speech, sensation, fertility mobility, pain, } \\
\text { dexterity, self-care, emotion, and cognition }\end{array}$ & $\begin{array}{c}15 \\
\text { (Self-administered) } \\
40 \\
\text { (Interviewer } \\
\text { administered) }\end{array}$ & Self; Proxy & Proprietary & Yes \\
\hline $\begin{array}{l}\text { 36-Item short form } \\
\text { survey (45) }\end{array}$ & $\begin{array}{l}\text { Survey which assesses eight health } \\
\text { concepts including limitations in physical, } \\
\text { social, or usual role activities, pain, mental } \\
\text { health, energy, fatigue, and general health } \\
\text { perceptions }\end{array}$ & 36 & Self & Proprietary & No \\
\hline EQ-5D (46) & $\begin{array}{l}\text { Measures five dimensions of health } \\
\text { including mobility, self-care, usual } \\
\text { activities, pain/discomfort, } \\
\text { anxiety/depression }\end{array}$ & 5 & Self/Proxy & Proprietary & Yes \\
\hline CarerQOL (47) & $\begin{array}{l}\text { Assesses seven dimensions of caregiving } \\
\text { burden including fulfillment, relationship } \\
\text { problems, mental health problems, } \\
\text { problems with daily activities, financial } \\
\text { problems, support, and physical problems }\end{array}$ & 8 & Self & $\begin{array}{l}\text { Non- } \\
\text { proprietary }\end{array}$ & Yes \\
\hline \multicolumn{6}{|l|}{ Financial toxicity } \\
\hline $\begin{array}{l}\text { Comprehensive score } \\
\text { of financial toxicity ( } 48 \text { ) }\end{array}$ & $\begin{array}{l}\text { Measures the financial distress } \\
\text { experienced by cancer patients }\end{array}$ & 11 & Self & Proprietary & $\mathrm{N} / \mathrm{A}$ \\
\hline $\begin{array}{l}\text { InCHARGE Financial } \\
\text { distress/financial } \\
\text { well-being scale (49) }\end{array}$ & $\begin{array}{l}\text { Survey designed to measure the level of } \\
\text { well-being and stress due to an individual's } \\
\text { personal financial state }\end{array}$ & 8 & Self & Proprietary & $N / A$ \\
\hline $\begin{array}{l}\text { Financial distress } \\
\text { questionnaire (50) }\end{array}$ & $\begin{array}{l}\text { Designed to assess a person's financial } \\
\text { ability to afford everyday items }\end{array}$ & 2 & Self & Proprietary & $\mathrm{N} / \mathrm{A}$ \\
\hline
\end{tabular}

The instruments listed in this table provide examples of tools used to in economic evaluations to measure family spillover effects. This is a non-exhaustive list. N/A, Not Applicable.

economic techniques and has been used in other pediatric populations (61). The economic burden following sepsis or other critical illness may be represented by out-of-pocket costs, work absenteeism, or change of employment, as family members typically provide substantial informal caregiving following a critical care hospitalization. Primary data collection on these measures and establishing a repository of data on family spillover effects will allow for a more complete measurement of the economic burden (41).

\section{A CALL TO ACTION}

Post-hospitalization and long-term outcomes have become a significant focus and priority of pediatric critical care and sepsis research. As laid out in the PICS-P framework, the physical, cognitive, emotional, and social health toll of critical illness should be measured bearing in mind the interdependent relationship of family and child (7). In order to effectively do so, consideration and inclusion of the economic and financial impact is required. Indeed, this was recognized as a priority to improve sepsis survivorship (62).

Providing support to families and children impacted by sepsis can take many forms. As families indicate a flexibility in work hours and location as fundamental to maintain a "work-life" balance (27), employers should be more accommodating in their support, perhaps applying the lessons-learned of remote work during the COVD-19 pandemic. Alternatively, respite care programs have been shown to be beneficial for the overall wellbeing of parents and caregivers $(63,64)$. In some instances, family members can be employed as home health care aides. However, such programs are not available in all states and often do not permit parent/guardian participation, thus the American Academy of Pediatrics has recommended expansion of these programs and inclusion of parents (65). Finally, financial support programs may provide benefit to caregivers (66). Grants and other patient assistance programs can help with out-of-pocket costs. However, these are often disease or medication specific, limiting their generalizability.

Financial burden and informal caregiving create undue stress and lowers health outcomes for children and adults alike. To capture the total burden of sepsis, both during inpatient hospitalization and in follow-up, the economic impact, including direct costs and time costs, must be considered. Measurement of spillover effects allows researchers to evaluate and compare the efficiency of interventions, which will become more important as we move to implement programs to limit long-term sequelae. Additionally, characterizing the burden of on family members will allow for the design of interventions targeted toward the 
caregiver. Through quantitative and qualitative methods, we can more readily understand the current economic issues of pediatric sepsis survivorship, inform policy to mitigate spillover effects, and comprehensively evaluate the impact of longitudinal sepsis interventions.

\section{DATA AVAILABILITY STATEMENT}

The original contributions presented in the study are included in the article/supplementary material, further inquiries can be directed to the corresponding author.

\section{REFERENCES}

1. Carlton EF, Barbaro RP, Iwashyna TJ, Prescott HC. Cost of pediatric severe sepsis hospitalizations. JAMA Pediatr. (2019) 173:986-7. doi: 10.1001/jamapediatrics.2019.2570

2. Killien EY, Farris RWD, Watson RS, Dervan LA, Zimmerman JJ. Healthrelated quality of life among survivors of pediatric sepsis. Pediatric Critical Care Medicine. (2019) 20:501-9. doi: 10.1097/PCC.0000000000001886

3. Zimmerman JJ, Banks R, Berg RA, Zuppa A, Newth CJ, Wessel D, et al. Trajectory of mortality and health-related quality of life morbidity following community-acquired pediatric septic shock. Crit Care Med. (2020) 48:329-37. doi: 10.1097/CCM.0000000000004123

4. Zimmerman JJ, Banks R, Berg RA, Zuppa A, Newth CJ, Wessel D, et al. Critical illness factors associated with long-term mortality and health-related quality of life morbidity following community-acquired pediatric septic shock. Crit Care Med. (2020) 48:319-28. doi: 10.1097/CCM.0000000000004122

5. Carlton EF, Kohne JG, Hensley MK, Prescott HC. Comparison of outpatient health care use before and after pediatric severe sepsis. Jama Netw Open. (2020) 3:e2015214. doi: 10.1001/jamanetworkopen.2020.15214

6. Carlton EF, Donnelly JP, Hensley MK, Cornell TT, Prescott HC. New medical device acquisition during pediatric severe sepsis hospitalizations. Crit Care Med. (2020) 48:725-31. doi: 10.1097/CCM.0000000000004272

7. Manning JC, Pinto NP, Rennick JE, Colville G, Curley MAQ. Conceptualizing post intensive care syndrome in children-the PICS-p framework. Pediatric Crit Care Med. (2018) 19:298-300. doi: 10.1097/PCC.0000000000001476

8. Watson RS, Choong K, Colville G, Crow S, Dervan LA, Hopkins RO, et al. Life after critical illness in children-toward an understanding of pediatric post-intensive care syndrome. J Pediatr. (2018) 198:16-24. doi: $10.1016 /$ j.jpeds.2017.12.084

9. Woodruff AG, Choong K. Long-term outcomes and the post-intensive care syndrome in critically ill children: a North American perspective. Children (Basel). (2021) 8:254. doi: 10.3390/children8040254

10. Rodríguez-Rey R, Alonso-Tapia J, Colville G. Prediction of parental posttraumatic stress, anxiety and depression after a child's critical hospitalization. J Crit Care. (2018) 45:149-55. doi: 10.1016/j.jcrc.2018.02.006

11. Barzallo DP. Spillover effects of long-term disabilities on close family members. Appl Heal Econ Heal Policy. (2018) 16:347-55. doi: 10.1007/s40258-018-0391-9

12. Wittenberg E, James LP, Prosser LA. Spillover effects on caregivers' and family members' utility: a systematic review of the literature. Pharmacoeconomics. (2019) 37:475-99. doi: 10.1007/s40273-019-00768-7

13. Hoefman R, Payakachat N. Exel Jvan, Kuhlthau K, Kovacs E, Pyne J, et al. Caring for a child with autism spectrum disorder and parents' quality of life: application of the CarerQol. J Autism Dev Disord. (2014) 44:1933-45. doi: 10.1007/s10803-014-2066-1

14. Lavelle TA, Weinstein MC, Newhouse JP, Munir K, Kuhlthau KA, Prosser LA. Economic burden of childhood autism spectrum disorders. Pediatrics. (2014) 133:e520-9. doi: 10.1542/peds.2013-0763

15. Brown CC, Tilford JM, Payakachat N, Williams DK, Kuhlthau KA, Pyne $\mathrm{JM}$, et al. Measuring health spillover effects in caregivers of children with autism spectrum disorder: a comparison of the EQ-5D-3L and SF-6D. Pharmacoeconomics. (2019) 37:609-20. doi: 10.1007/s40273-019-00789-2

\section{AUTHOR CONTRIBUTIONS}

EC, HP, and LP contributed to the concept and design of the perspective. EC drafted the initial manuscript and tables. EC, HP, LP, and SW critically evaluated and revised the manuscript. All authors approved the manuscript.

\section{FUNDING}

EC reports support from grants KL2 TR 002241 and UL1 TR 002240.

16. Lavelle TA, Wittenberg E, Lamarand K, Prosser LA. Variation in the spillover effects of illness on parents, spouses, and children of the chronically ill. Appl Health Econ Health Policy. (2014) 12:117-24. doi: 10.1007/s40258-014-0079-8

17. Basu A, Meltzer D. Implications of spillover effects within the family for medical cost-effectiveness analysis. J Health Econ. (2005) 24:751-73. doi: $10.1016 /$ j.jhealeco.2004.12.002

18. Wittenberg E, Prosser LA. Health as a family affair. New Engl J Med. (2016) 374:1804-6. doi: 10.1056/NEJMp1604456

19. Grosse SD, Pike J, Soelaeman R, Tilford JM. Quantifying family spillover effects in economic evaluations: measurement and valuation of informal care time. Pharmacoeconomics. (2019) 37:461-73. doi: 10.1007/s40273-019-00782-9

20. Hoefman RJ, Exel J. van, Brouwer WBF. The monetary value of informal care: obtaining pure time valuations using a discrete choice experiment. Pharmacoeconomics. (2019) 37:531-40. doi: 10.1007/s40273-018-0724-4

21. Prosser LA, Lamarand K, Gebremariam A, Wittenberg E. Measuring family HRQoL spillover effects using direct health utility assessment. Med Decis Maing. (2015) 35:81-93. doi: 10.1177/0272989X14541328

22. Graj E, Muscara F, Anderson V, Hearps S, McCarthy M. Quality of life in parents of seriously Ill/injured children: a prospective longitudinal study. Qual Life Res. (2021) 30:193-202. doi: 10.1007/s11136-020-02624-0

23. Hordijk J, Verbruggen S, Vanhorebeek I, Berghe GVden, Utens E, Joosten $\mathrm{K}$, et al. Health-related quality of life of children and their parents 6 months after children's critical illness. Qual Life Res. (2020) 29:179-89. doi: 10.1007/s11136-019-02347-x

24. Bassett HK, Coller RJ, Beck J, Hummel K, Tiedt KA, Flaherty B, et al. Financial difficulties in families of hospitalized children. J Hosp Med. (2020) 15:652-8. doi: $10.12788 /$ jhm.3500

25. Hope S, Pearce A, Whitehead M, Law C. Effects of child long-term illness on maternal employment: longitudinal findings from the UK millennium cohort study. Eur J Public Health. (2017) 27:48-52. doi: 10.1093/eurpub/ckw132

26. Kish AM, Newcombe PA, Haslam DM. Working and caring for a child with chronic illness: a review of current literature. Child Care Health Dev. (2018) 44:343-54. doi: $10.1111 /$ cch. 12546

27. George A, Vickers MH, Wilkes L, Barton B. Working and caring for a child with chronic illness: barriers in achieving work-family balance. J Manage Organ. (2008) 14:59-72. doi: 10.5172/jmo.2008.14.1.59

28. Brown S, Herr J, Roy R, Klerman JA. Employee and Worksite Perspectives of the FMLA: Who is Eligible? In: Produced for the U.S. Department of Labor, Chief Evaluation Office. Rockville, MD: Abt Associates Inc. (2020).

29. Chung PJ, Garfield CF, Elliott MN, Carey C, Eriksson C, Schuster MA. Need for and use of family leave among parents of children with special health care needs. Pediatrics. (2007) 119:e1047-55. doi: 10.1542/peds.20062337

30. Prout AJ, Talisa VB, Carcillo JA, Mayr FB, Angus DC, Seymour CW, et al. Children with chronic disease bear the highest burden of pediatric sepsis. $J$ Pediatr. (2018) 199:194-199.e1. doi: 10.1016/j.jpeds.2018.03.056

31. Buysse CMP, Raat H, Hazelzet JA, Hop WCJ, Maliepaard M, Joosten KFM. Surviving meningococcal septic shock: health consequences and quality of life in children and their parents up to 2 years after pediatric intensive care unit discharge. Crit Care Med. (2008) 36:596-602. doi: 10.1097/01.CCM.0000299740.65484.CA 
32. Wintermann G-B, Weidner K, Strauß B, Rosendahl J, Petrowski K. Predictors of posttraumatic stress and quality of life in family members of chronically critically ill patients after intensive care. Ann Intensive Care. (2016) 6:69. doi: 10.1186/s13613-016-0174-0

33. Gawlytta R, Brunkhorst F, Niemeyer H, Boettche M, Knaevelsrud C, Rosendahl J. Dyadic post-traumatic stress after intensive care: case report of a sepsis patient and his wife. Intens Crit Care Nur. (2020) 58:102806. doi: 10.1016/j.iccn.2020.102806

34. Davydow DS, Hough CL, Langa KM, Iwashyna TJ. Depressive symptoms in spouses of older patients with severe sepsis. Crit Care Med. (2012) 40:2335-41. doi: 10.1097/CCM.0b013e3182536a81

35. Falkson S, Knecht C, Hellmers C, Metzing S. the perspective of families with a ventilator-dependent child at home. A literature review. J Pediatric Nurs. (2017) 36:213-24. doi: 10.1016/j.pedn.2017.06.021

36. Carlton EF, Kohne JG, Shankar-Hari M, Prescott HC. Readmission diagnoses after pediatric severe sepsis hospitalization. Crit Care Med. (2019) 47:583-90. doi: 10.1097/CCM.0000000000003646

37. Tiru B, DiNino EK, Orenstein A, Mailloux PT, Pesaturo A, Gupta A, et al. The economic and humanistic burden of severe sepsis. Pharmacoeconomics. (2015) 33:925-37. doi: 10.1007/s40273-015-0282-y

38. Sanders GD, Neumann PJ, Basu A, Brock DW, Feeny D, Krahn M, et al. Recommendations for conduct, methodological practices, and reporting of cost-effectiveness analyses: second panel on cost-effectiveness in health and medicine. JAMA. (2016) 316:1093-103. doi: 10.1001/jama.2016.12195

39. Fayed N, Cameron S, Fraser D, Cameron JI, Al-Harbi S, Simpson R, et al. Priority outcomes in critically ill children: a patient and parent perspective. Am J Crit Care. (2020) 29:e94-e103. doi: 10.4037/ajcc2020188

40. Higgins AM, Harris AH. Health economic methods: cost-minimization, costeffectiveness, cost-utility, and cost-benefit evaluations. Crit Care Clin. (2012) 28:11-24. doi: 10.1016/j.ccc.2011.10.002

41. Higgins AM, Brooker JE, Mackie M, Cooper DJ, Harris AH. Health economic evaluations of sepsis interventions in critically ill adult patients: a systematic review. J Intensive Care. (2020) 8:5. doi: 10.1186/s40560-019-0412-2

42. Maddux AB, Pinto N, Fink EL, Hartman ME, Nett S, Biagas K, et al. Postdischarge outcome domains in pediatric critical care and the instruments used to evaluate them: a scoping review. Crit Care Med. (2020) 48:e1313-21. doi: 10.1097/CCM.0000000000004595

43. Terp K, Sjöström-Strand A. Parents' experiences and the effect on the family two years after their child was admitted to a PICU-An interview study. Intens Crit Care Nur. (2017) 43:143-8. doi: 10.1016/j.iccn.2017.06.003

44. Horsman J, Furlong W, Feeny D, Torrance G. The Health Utilities Index (HUIß): concepts, measurement properties and applications. Health Qual Life Out. (2003) 1:54. doi: 10.1186/1477-7525-1-54

45. Ware JE, Sherbourne CD. The MOS 36-ltem short-form health survey (SF36). Med Care. (1992) 30:473-83. doi: 10.1097/00005650-199206000-00002

46. Rabin R, Charro F de. EQ-SD: a measure of health status from the EuroQol Group. Ann Med. (2009) 33:337-43. doi: 10.3109/07853890109002087

47. Brouwer WBF, Exel NJA. van, Gorp B van, Redekop WK. The CarerQol instrument: a new instrument to measure care-related quality of life of informal caregivers for use in economic evaluations. Qual Life Res. (2006) 15:1005-21. doi: 10.1007/s11136-005-5994-6

48. Souza JA, Yap BJ, Hlubocky FJ, Wroblewski K, Ratain MJ, Cella D, et al. The development of a financial toxicity patient-reported outcome in cancer: the COST measure. Cancer. (2014) 120:3245-53. doi: 10.1002/cncr.28814

49. Prawitz AD, Garman ET, Sorhaindo B, O'Neill B, Kim J, Drentea P. InCharge financial distress/financial well-being scale: development, administration, and score interpretation. Financ Couns Plan. (2006) 17:34-50. doi: 10.1037/t60365-000

50. Mady LJ Lyu L, Owoc MS, Peddada SD, Thomas TH, Sabik LM, et al. Understanding financial toxicity in head and neck cancer survivors. Oral Oncol. (2019) 95:187-93. doi: 10.1016/j.oraloncology.2019.06.023

51. Abela KM, Wardell D, Rozmus C, LoBiondo-Wood G. Impact of pediatric critical illness and injury on families: an updated systematic review. J Pediatric Nurs. (2020) 51:21-31. doi: 10.1016/j.pedn.2019.10.013

52. Killien EY, Loftis LL, Clark JD, Muszynski JA, Rissmiller BJ, Singleton $\mathrm{MN}$, et al. Health-related quality of life outcome measures for children surviving critical care: a scoping review. Qual Life Res. (2021). doi: 10.1007/s11136-021-02928-9. [Epub ahead of print].
53. Fitzgerald C, George S, Somerville R, Linnane B, Fitzpatrick P. Caregiver burden of parents of young children with cystic fibrosis. J Cyst Fibros. (2018) 17:125-31. doi: 10.1016/j.jcf.2017.08.016

54. Travlos V, Patman S, Downs J, Hince D, Wilson AC. Parent carer quality of life and night-time attendance in non-ambulant youth with neuromuscular disorders. Dev Neurorehabil. (2021) 24:456-65. doi: 10.1080/17518423.2021.1908440

55. DeKoven M, Karkare S, Lee WC, Kelley LA, Cooper DL, Pham H, et al. Impact of haemophilia with inhibitors on caregiver burden in the United States. Haemophilia. (2014) 20:822-30. doi: 10.1111/hae.12501

56. Buysse CMP, Vermunt LCAC, Raat H, Hazelzet JA, Hop WCJ, Utens EMWJ, et al. Surviving meningococcal septic shock in childhood: long-term overall outcome and the effect on health-related quality of life. Crit Care. (2010) 14:R124-8. doi: 10.1186/cc9087

57. Herdman M, Cole A, Hoyle CK, Coles V, Carroll S, Devlin N. Sources and characteristics of utility weights for economic evaluation of pediatric vaccines: a systematic review. Value Health. (2016) 19:255-66. doi: $10.1016 /$ j.jval.2015.11.003

58. Garza AG, Wyrwich KW. Health utility measures and the standard gamble. Acad Emerg Med. (2003) 10:360-3. doi: 10.1111/j.1553-2712.2003.tb01349.x

59. Matza LS, Boye KS, Feeny DH, Johnston JA, Bowman L, Jordan JB. Impact of caregiver and parenting status on time trade-off and standard gamble utility scores for health state descriptions. Health Qual Life Out. (2014) 12:48. doi: 10.1186/1477-7525-12-48

60. Ornstein KA, Garrido MM, Siu AL, Bollens-Lund E, Rahman O-K, Kelley AS. An examination of downstream effects of bereavement on healthcare utilization for surviving spouses in a national sample of older adults. Pharmacoeconomics. (2019) 37:585-96. doi: 10.1007/s40273-019-00787-4

61. Rose AM, Grosse SD, Garcia SP, Bach J, Kleyn M, et al. The financial and time burden associated with phenylketonuria treatment in the United States. Mol Genet Metab Rep. (2019) 21:100523. doi: 10.1016/j.ymgmr.2019.1 00523

62. Prescott HC, Iwashyna TJ, Blackwood B, Calandra T, Chlan LL, Choong $\mathrm{K}$, et al. Understanding and enhancing sepsis survivorship: priorities for research and practice. Am J Respir Crit Care Med. (2019) 200:972-981. doi: 10.1164/rccm.201812-2383CP

63. Whitmore KE, Snethen J. Respite care services for children with special healthcare needs: parental perceptions. J Spec Pediatr Nurs. (2018) 23:e12217. doi: 10.1111 /jspn. 12217

64. Carter KB, Mandrell BN. Development of a respite care program for caregivers of pediatric oncology patients and their siblings. J Pediatr Oncol Nurs. (2013) 30:109-14. doi: 10.1177/1043454212473652

65. Simpser E, Hudak ML, Financing SOHC, Committee on Child Health. Financing of pediatric home health care. Pediatrics. (2017) 139:e20164202. doi: 10.1542/peds.2016-4202

66. Chen Y-M, Hedrick SC, Young HM, A. pilot evaluation of the family caregiver support program. Eval Program Plan. (2010) 33:113-9. doi: 10.1016/j.evalprogplan.2009. 08.002

Conflict of Interest: The authors declare that the research was conducted in the absence of any commercial or financial relationships that could be construed as a potential conflict of interest.

Publisher's Note: All claims expressed in this article are solely those of the authors and do not necessarily represent those of their affiliated organizations, or those of the publisher, the editors and the reviewers. Any product that may be evaluated in this article, or claim that may be made by its manufacturer, is not guaranteed or endorsed by the publisher.

Copyright () 2021 Carlton, Weiss, Prescott and Prosser. This is an open-access article distributed under the terms of the Creative Commons Attribution License (CC BY). The use, distribution or reproduction in other forums is permitted, provided the original author(s) and the copyright owner(s) are credited and that the original publication in this journal is cited, in accordance with accepted academic practice. No use, distribution or reproduction is permitted which does not comply with these terms. 